\title{
Enhanced Copper-Temozolomide Interactions by Protein for Chemotherapy against Glioblastoma Multiforme
}

\author{
Xiao Li,${ }^{\dagger}$ Fenli Shao, ${ }^{\dagger}$ Jian Sun,${ }^{\dagger}$ Ke Du, ${ }^{\dagger}$ Yang Sun, ${ }^{\dagger}$ and Fude Feng ${ }^{*}, \dagger$ \\ $\dagger$ Key Laboratory of High Performance Polymer Material and Technology of Ministry of Education, \\ Department of Polymer Science \& Engineering, School of Chemistry \& Chemical Engineering, \\ Nanjing University, Nanjing 210023, P. R. China \\ $¥$ State Key Laboratory of Pharmaceutical Biotechnology, Chemistry and Biomedicine Innovation \\ Center (ChemBIC), School of Life Sciences, Nanjing University, Nanjing 210023, P. R. China
}

*Email: fengfd@nju.edu.cn

$\begin{array}{lr}\text { Figure S1. } & \text { S-2 }\end{array}$

Figure S2. $\quad$ S-3

Figure S3. $\quad$ S-3

$\begin{array}{lr}\text { Figure } \mathbf{S 4} & \text { S-3 }\end{array}$

Figure S5.

$\begin{array}{lr}\text { Figure S6. } & \text { S-4 }\end{array}$

Figure S7. S-5

$\begin{array}{lr}\text { Figure S8. } & \text { S-5 }\end{array}$

$\begin{array}{lr}\text { Figure S9. } & \text { S-6 }\end{array}$

$\begin{array}{lr}\text { Figure S10. } & \text { S-6 }\end{array}$

$\begin{array}{lr}\text { Figure S11. } & \text { S-7 }\end{array}$

$\begin{array}{lr}\text { Figure S12. } & \text { S-7 }\end{array}$

$\begin{array}{lr}\text { Figure S13. } & \text { S-8 }\end{array}$

$\begin{array}{ll}\text { Figure S14. } & \text { S-8 }\end{array}$ 

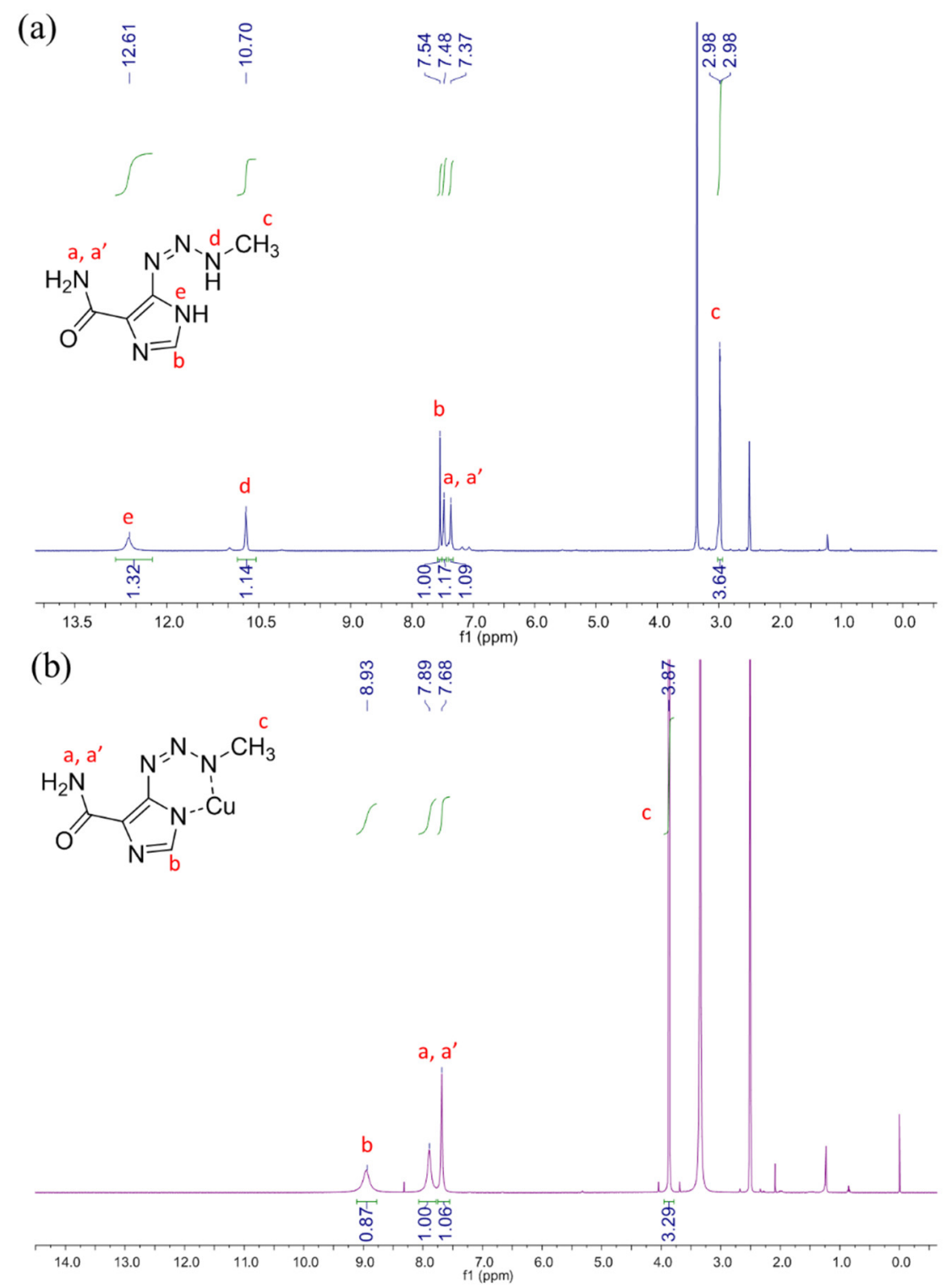

(c)

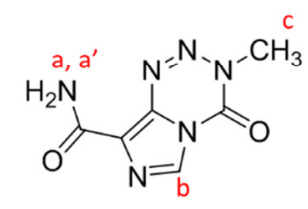

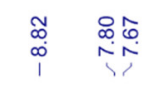

\section{$\stackrel{\substack{\infty \\ i}}{i}$}
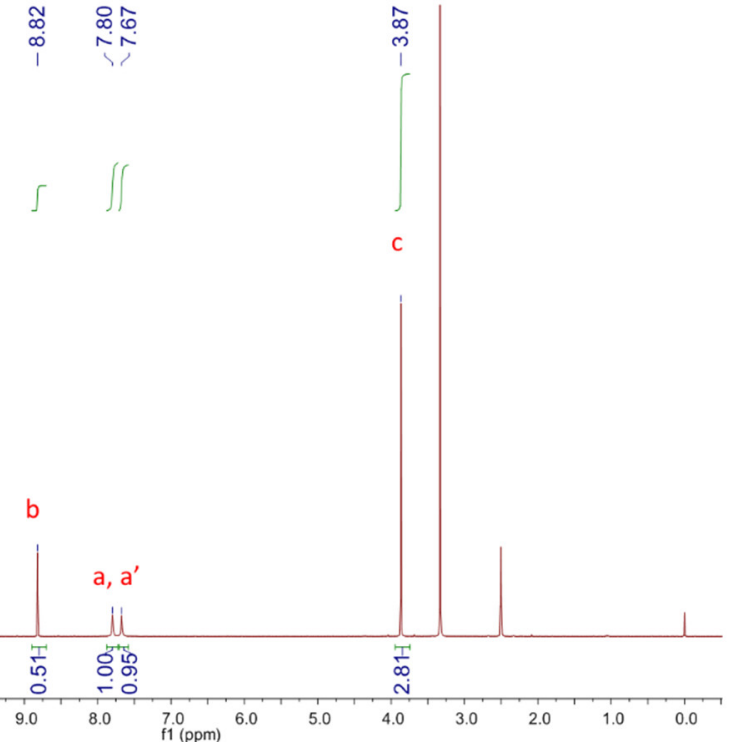

Figure S1. ${ }^{1} \mathrm{H}$ NMR spectra of (a) MTIC, (b) Cu-MTIC and (c) TMZ in DMSO- $d^{6}$ (400 MHz). 


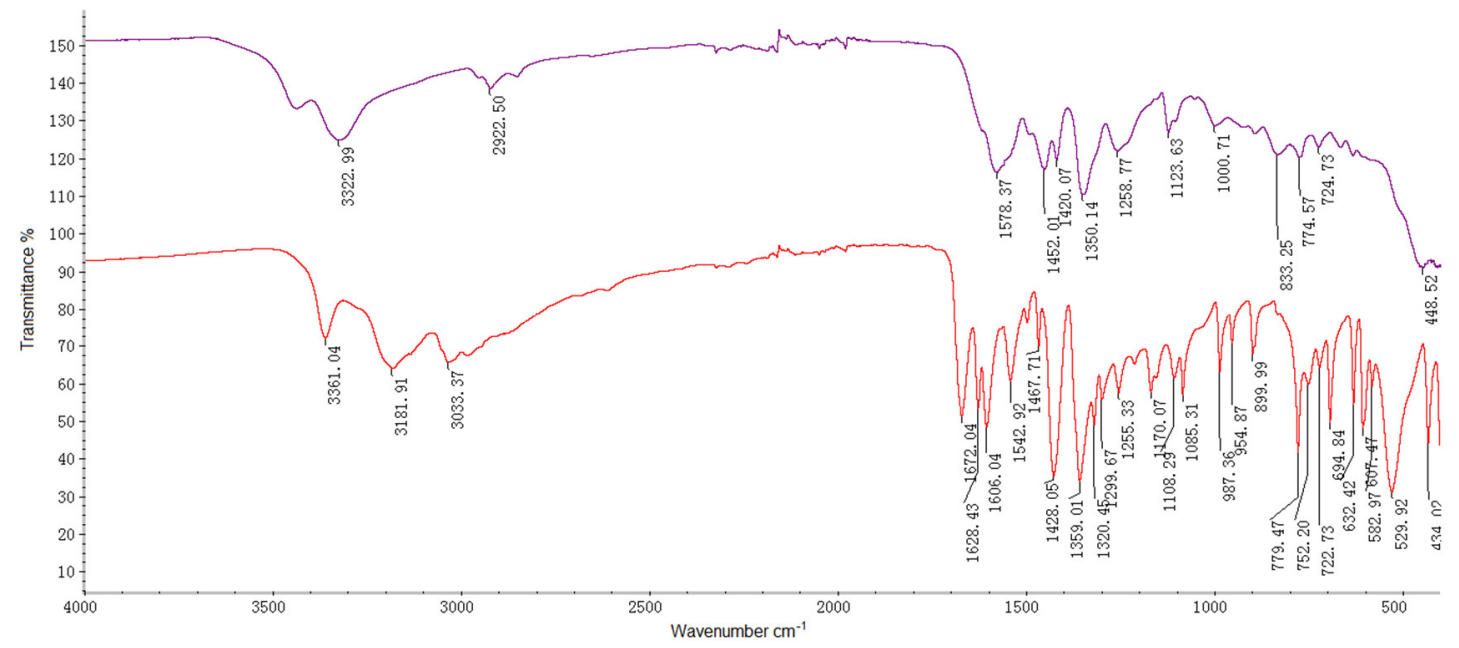

Figure S2. FT-IR spectra of MTIC (red) and Cu-MTIC (purple).
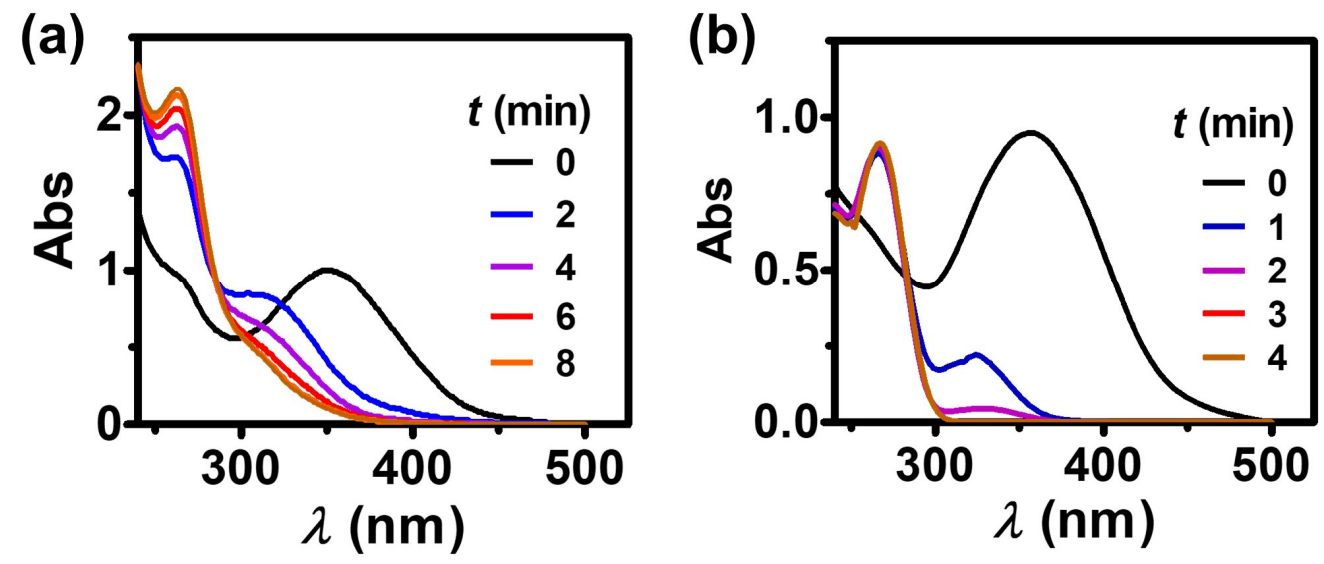

Figure S3. The UV-vis absorption spectra of the solution containing Cu-MTIC $(100 \mu \mathrm{M})$ (a) at 0-8 min after addition of $2 \mathrm{mM} \mathrm{Na}_{2} \mathrm{~S}$, and (b) at 0-4 min after acidification to $c a$. $\mathrm{pH} 2$. Initial absorption of $\mathrm{Cu}-\mathrm{MTIC}$ was normalized at $355 \mathrm{~nm}$.

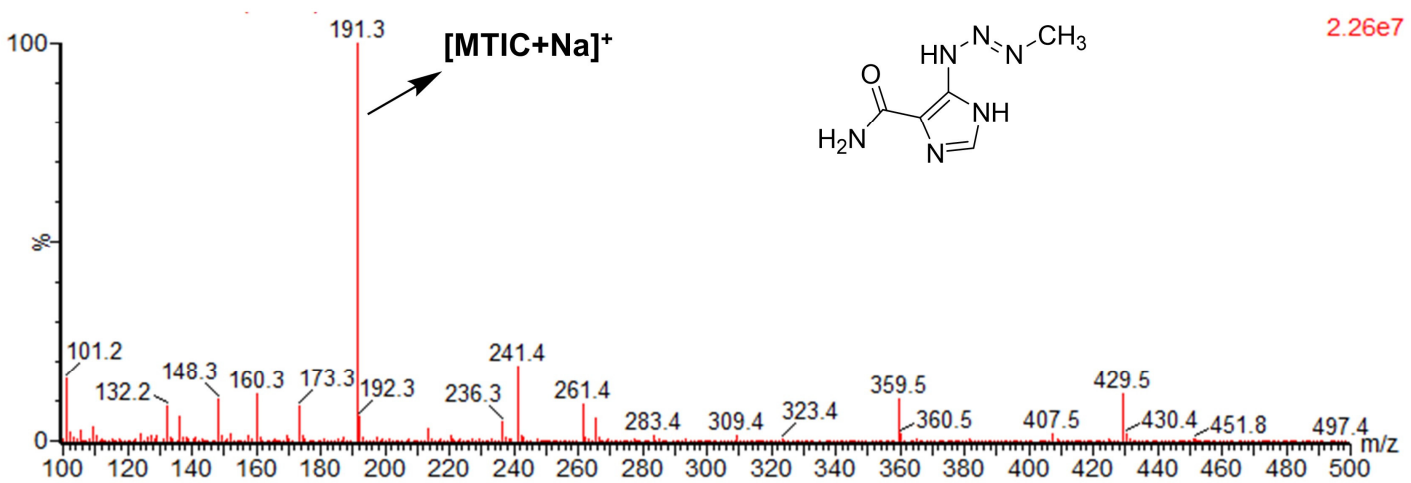

Figure S4. Mass spectrum of $\mathrm{Na}_{2} \mathrm{~S}$-treated $\mathrm{Cu}-\mathrm{MTIC}$. 


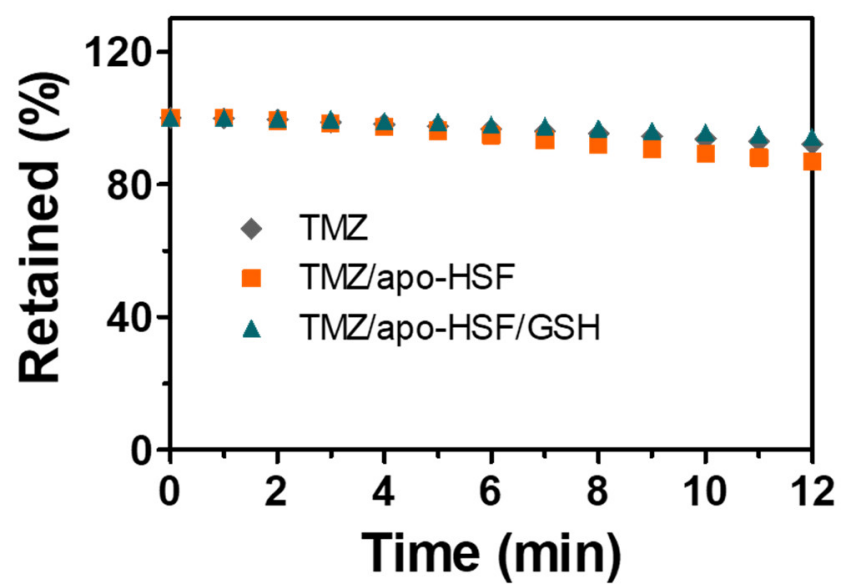

Figure S5. Stability of TMZ $(100 \mu \mathrm{M})$ in the presence of apo-HSF $(1.2 \mu \mathrm{M})$ or apo-HSF $(1.2$ $\mu \mathrm{M}) / \mathrm{GSH}(1 \mathrm{mM})$ in PBS ( $\mathrm{pH}$ 7.4).
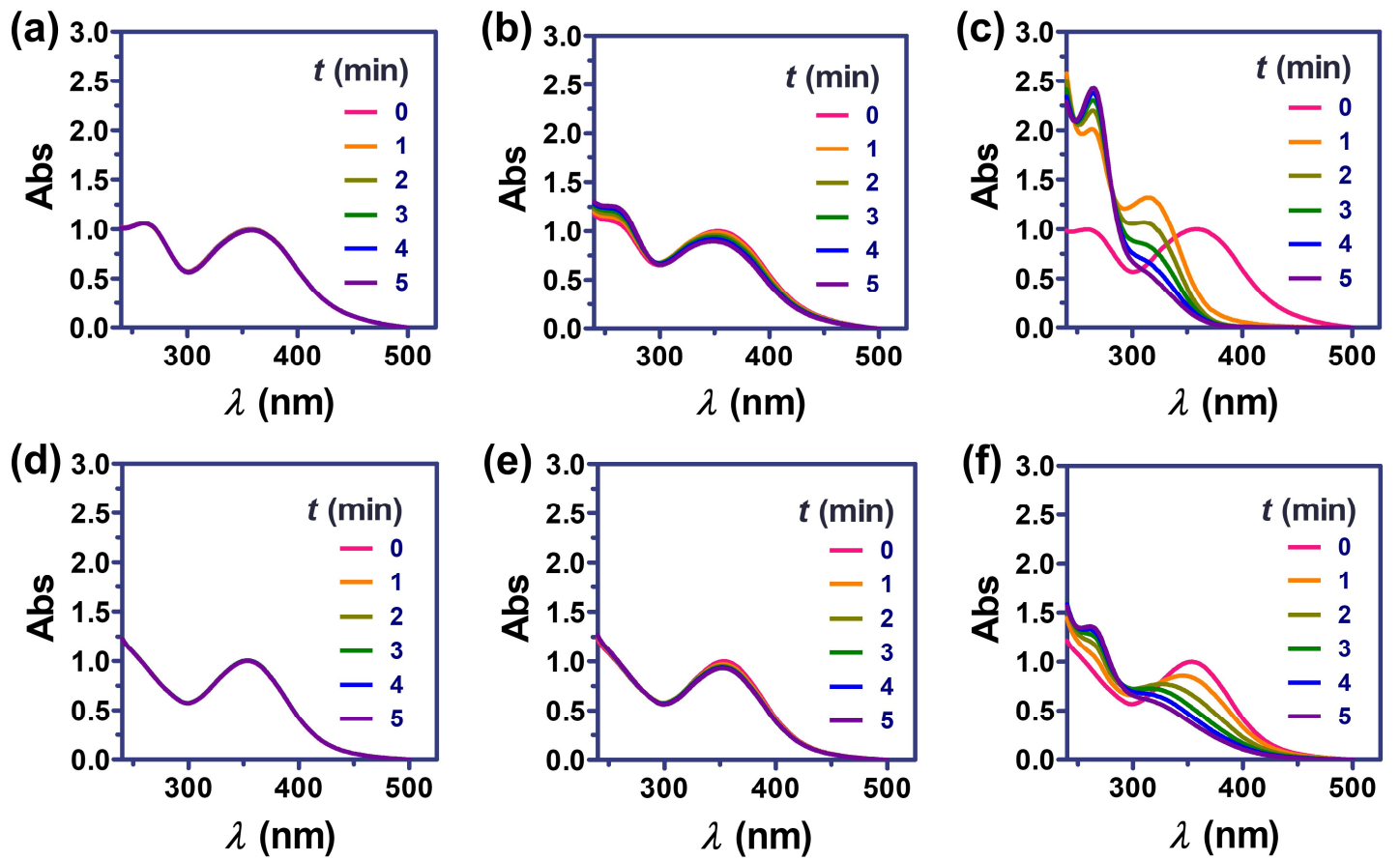

Figure S6. UV-vis spectra of (a-c) Cu-MTIC and (d-f) CuNPs at 0-5 min post addition of GSH at various concentrations. GSH concentration: (a) and (d), $0 \mathrm{mM}$; (b) and (e), $0.1 \mathrm{mM}$; (c) and (f), $2 \mathrm{mM})$. 


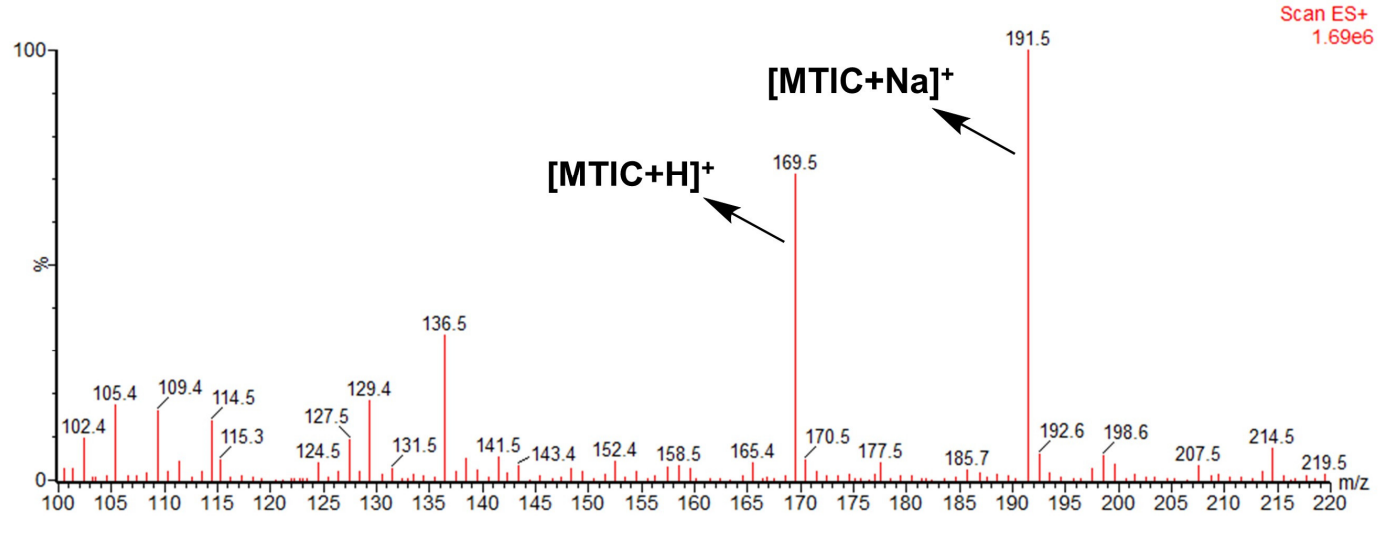

Figure S7. Mass spectrum of UPLC-analyzed sample that was collected from the filtrate. The filtrate was obtained by ultracentrifugation of the reaction mixture of GSH $(2 \mathrm{mM})$ and CuNPs $(100$ $\mu \mathrm{M})$.
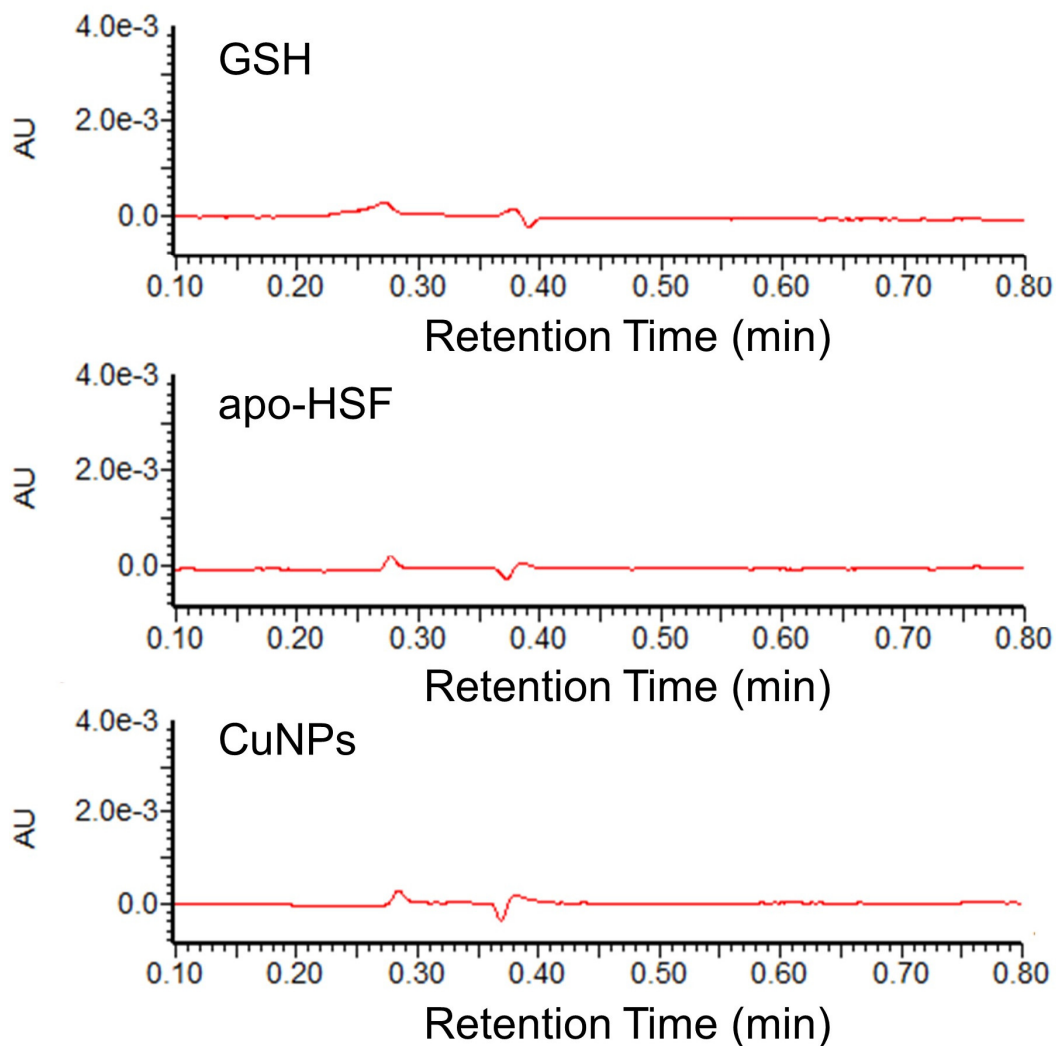

Figure S8. UPLC traces of GSH ( $2 \mathrm{mM})$, apo-HSF and CuNPs $(100 \mu \mathrm{M})$ in $330 \mathrm{~nm}$ PDA channel. Prefiltration with a membrane (MWCO $50 \mathrm{kDa}$ ) was performed before loading samples. 


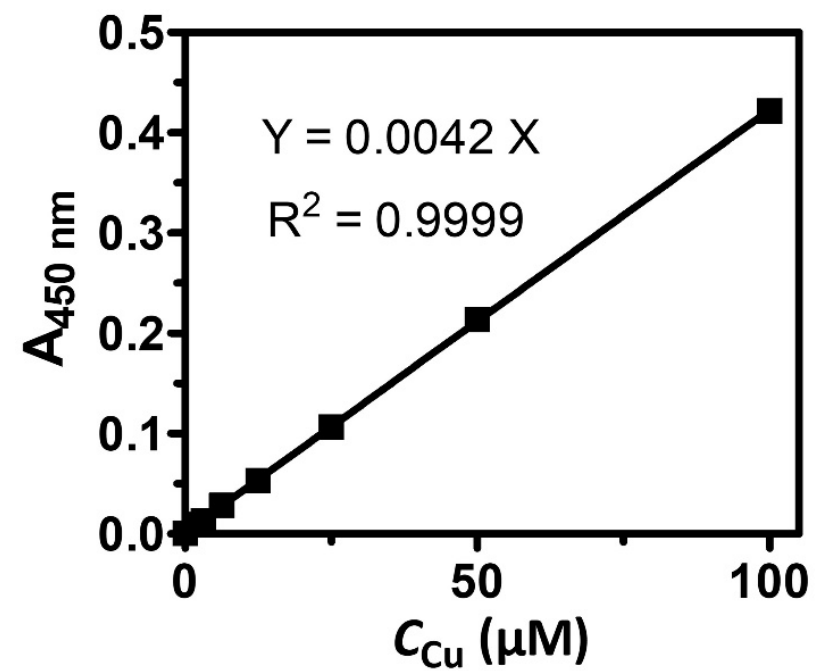

Figure S9. Linear fitting of the standard curve by plotting absorption intensity at $450 \mathrm{~nm}\left(\mathrm{~A}_{450 \mathrm{~nm}}\right)$ as a function of $\mathrm{Cu}$ concentration $\left(C_{\mathrm{Cu}}\right)$ with $\mathrm{CuDDTC}$ as reference.

(a)
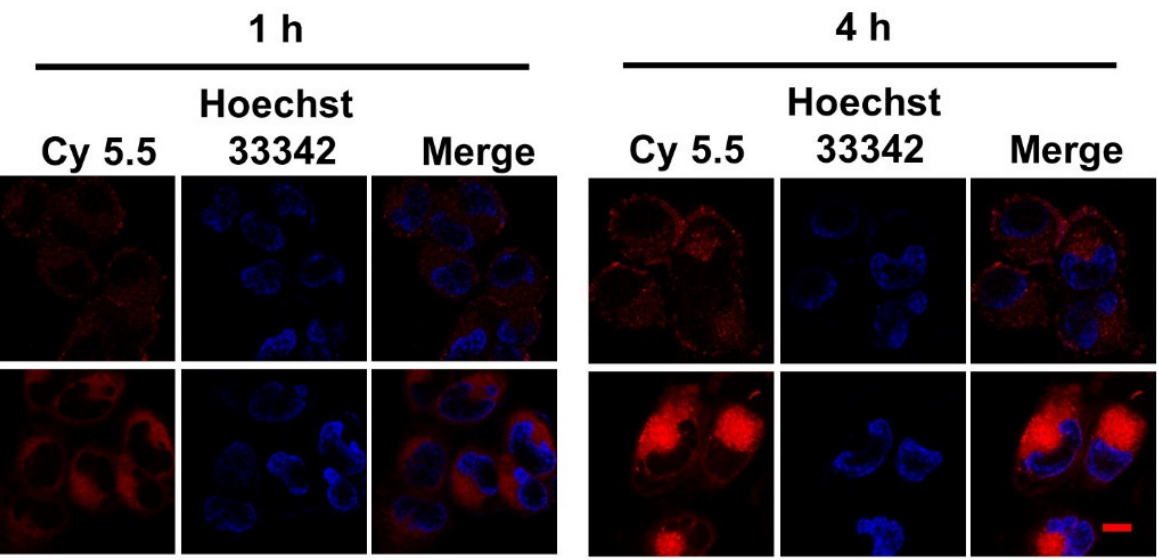

(b)
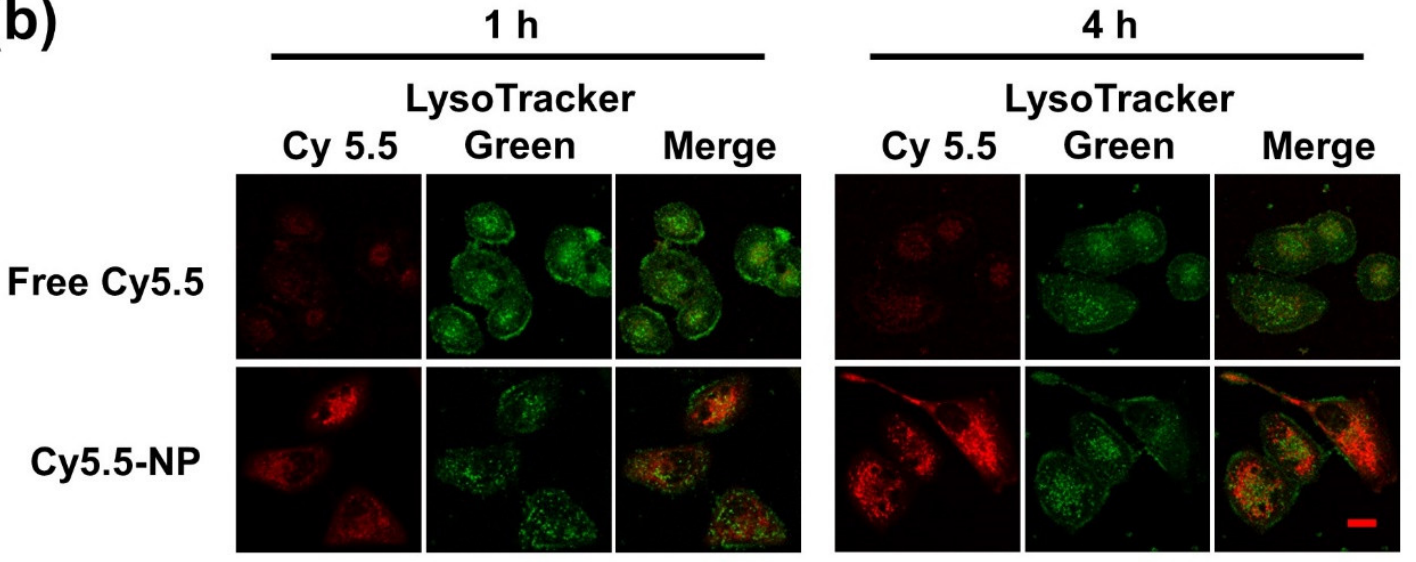

Figure S10. CLSM images of T98G cells $1 \mathrm{~h}$ or $4 \mathrm{~h}$ after incubation with free Cy5.5 or Cy5.5-NP $(0.15 \mu \mathrm{M})$. The nucleus and lysosome compartments were stained by (a) Hoechst 33342 and (b) LysoTracker Green, respectively. Scale bar, $20 \mu \mathrm{m}$. 
(a)

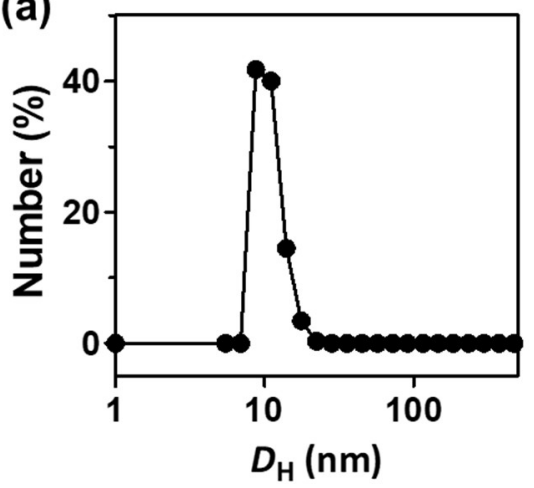

(b)

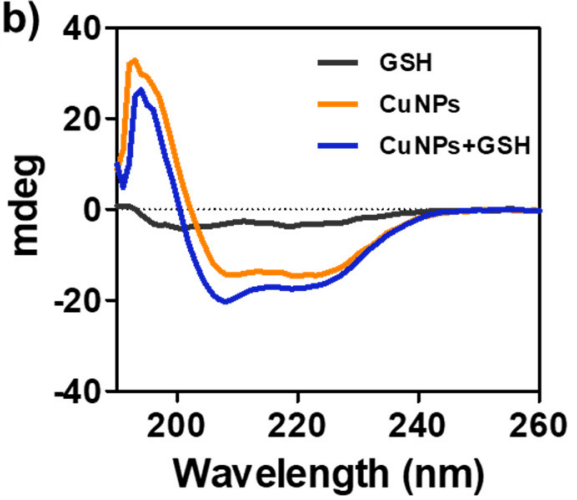

Figure S11. (a) Particle size of CuNPs after interaction with GSH (1 mM) for 1 hour. (b) Circular dichroism spectra of GSH, CuNPs and GSH (1 mM)-treated CuNPs.

(a)

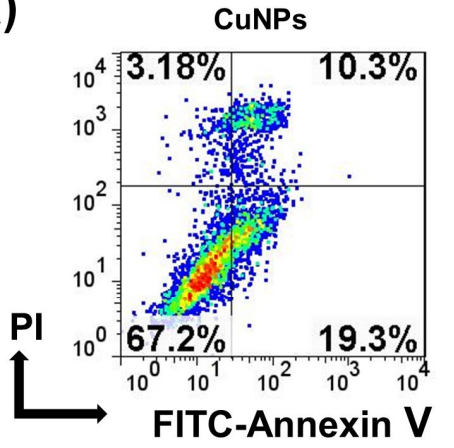

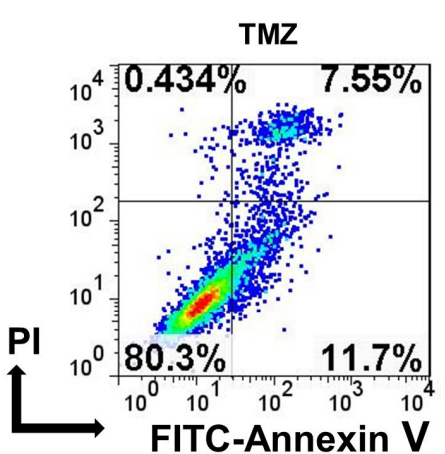

(b)

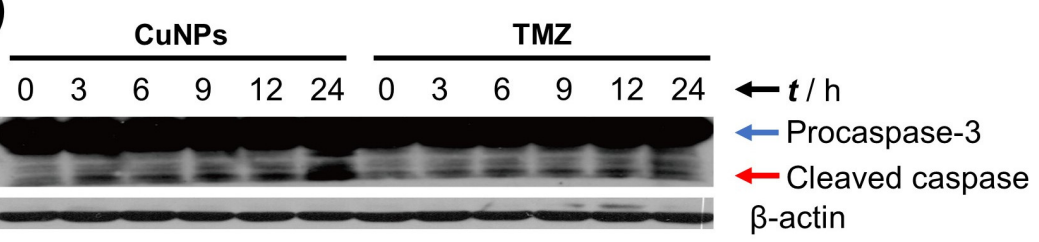

(c)

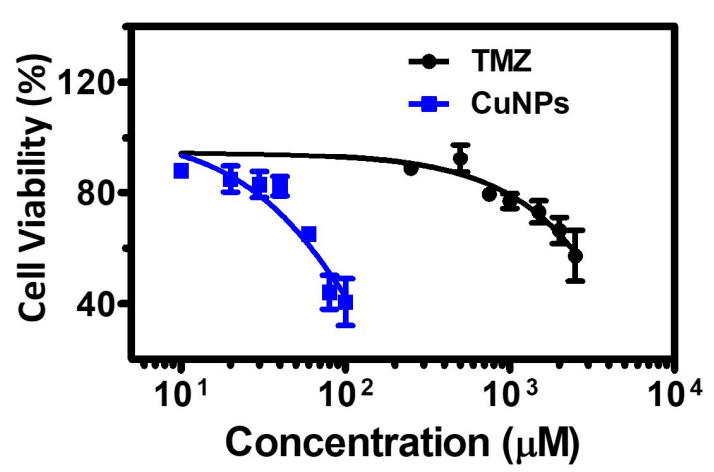

Figure S12. Cytotoxicity with TMZ-resistance glioblastoma T98G cells. (a) Flow cytometry analysis of T98G cells after 24-h incubation with TMZ $(100 \mu \mathrm{M})$ or CuNPs $(100 \mu \mathrm{M})$. The cells were stained with PI and FITC-Annexin V before analysis. (b) Western blot analysis of procaspase3 and its cleaved products in T98G cells. $\beta$-actin was used as a reference. (c) Viabilities of T98G cells treated with varied concentrations of different species for $72 \mathrm{~h}$. 
(a)

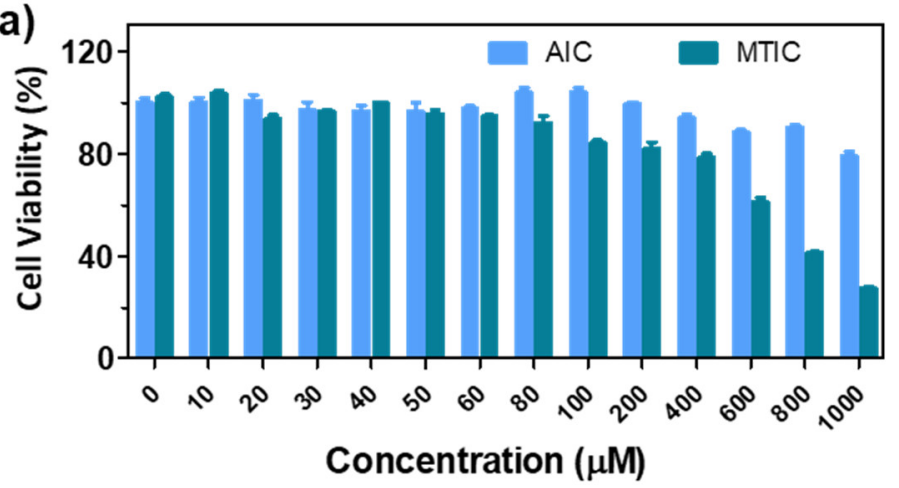

(c)

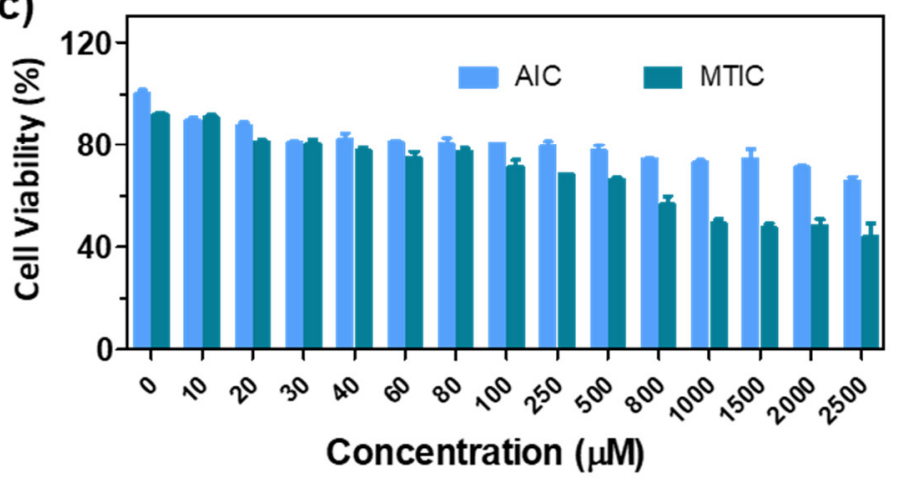

(b)

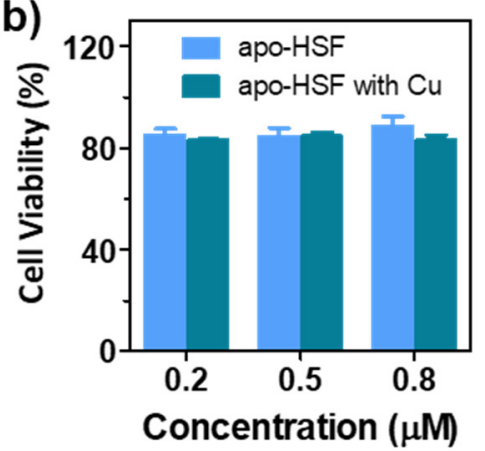

(d)

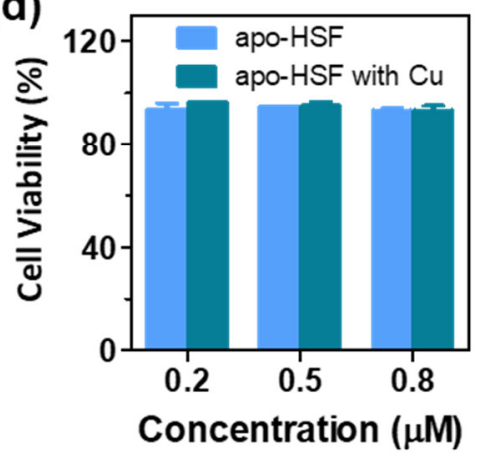

Figure S13. Cell viabilities of (a-b) U87MG and (c-d) T98G cells after 72-h treatment with AIC, MTIC, apo-HSF and apo-HSF with $\mathrm{Cu}$ (200:1 relative to apo-HSF in molar ratio).

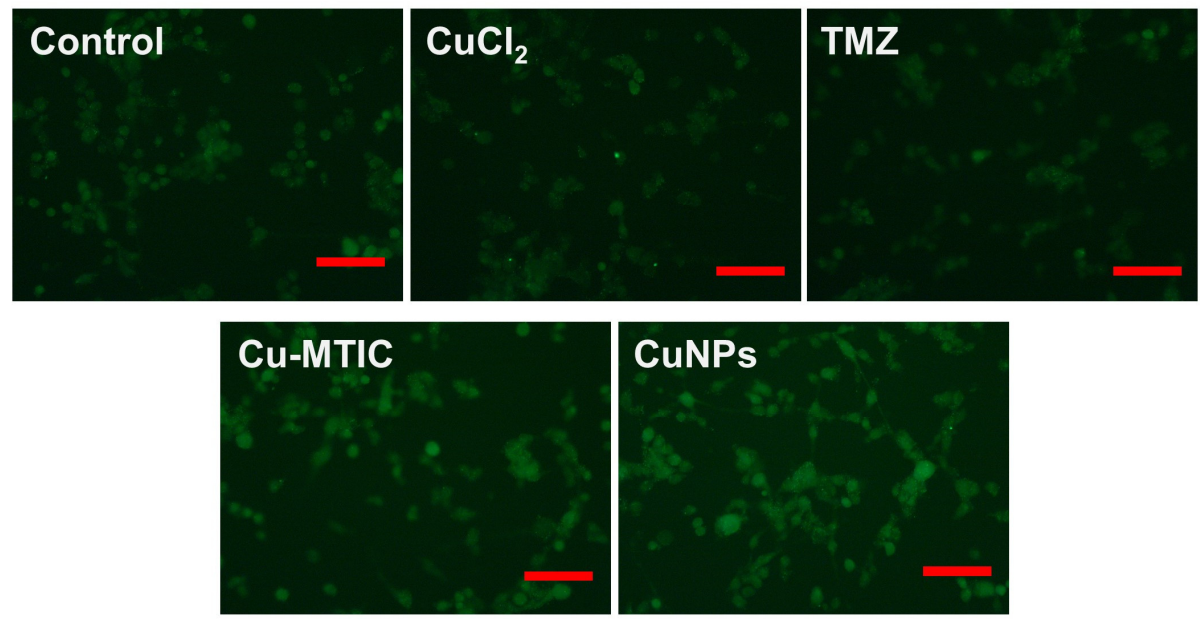

Figure S14. Fluorescent images of U87MG cells after 24-h incubation with $\mathrm{PBS}, \mathrm{CuCl}_{2}(100 \mu \mathrm{M})$, TMZ $(100 \mu \mathrm{M})$, Cu-MTIC $(100 \mu \mathrm{M})$ or CuNPs $(100 \mu \mathrm{M})$. The cells were treated by DCFH-DA for $20 \mathrm{~min}$ before imaging. Scale bar, $100 \mu \mathrm{m}$. 